\title{
Desafios da proteção do patrimônio cultural industrial de Juiz de Fora
}

Julio Cesar Ribeiro Sampaio*

\section{Resumo}

A cidade de Juiz de Fora, Minas Gerais, Brasil, possui trajetória histórica fortemente correlacionada com a industrialização. O auge desta identificação ocorreu entre as décadas de 1880 e de 1930 quando esta cidade foi considerada o principal pólo industrial da região e um dos mais significativos do país. Em um dado momento do final do século 19, Juiz de Fora foi denominada "Manchester Mineira" em função da proliferação de fábricas com aspectos semelhantes aos padrões arquitetônicos britânicos.

A partir da década de 1930 a industrialização entrou em crise em Juiz de Fora e vários estabelecimentos fabris entraram em processo de obsolescência e encerrarem suas atividades. Poucos exemplares tradicionais conseguiram sobreviver aos descasos, demolições e reformas que comprometeram significativamente a autenticidade e integridade dos aspectos arquitetônicos originais. Deste grupo restam apenas onze prédios que se encontram parcialmente protegidos pelas autoridades locais. Somente um deles possui proteção integral. Dentro do universo do patrimônio industrial de Juiz de Fora se destaca a Fábrica dos Ingleses que se constitui num exemplar paradigmático da citada trajetória de apogeu, crise, desprezo e critérios de proteção polêmicos. Fundada em 1883 e considerada a primeira fábrica de grande porte da cidade, o complexo industrial passou por algumas modificações e expansões até terminar as atividades em meados da década de 1980. Após anos de abandono foi parcialmente demolido no final da década de 1990. As partes remanescentes do conjunto original, um galpão, unidade residencial e uma chaminé do início do século 20, foram tombadas em 2003 e 2004. O terreno resultante da demolição foi destinado para a construção de um complexo de uso misto cuja ocupação ainda não se completou.

A partir da análise da controvertida trajetória da Fábrica dos Ingleses, pretende-se neste trabalho propor a reavaliação da política de proteção e de conservação de Juiz de Fora, especialmente em relação ao conjunto de estabelecimentos industriais tradicionais da cidade cuja importância histórica, artística e afetiva demandaria um 
outro tipo de atitude. Esta reavaliação propõe como referência a literatura especializada de conservação com ênfase no patrimônio industrial, sobretudo das experiências britânicas em função da importância deste país no cenário internacional deste tema e pelas semelhanças comentadas acima com as circunstâncias de Juiz de Fora.

Palavras-chave: Preservação arquitetônica industrial. Patrimônio industrial, Juiz de Fora, MG, Brasil. Fábrica dos Ingleses, Juiz de Fora, MG.

\section{Daring the protection of the Juiz de Fora industrial heritage}

\section{ABSTRACT}

The historical trajectory of Juiz de Fora, Minas Gerais State, Brazil is closely correlated with industrialization, whose peak occurred between 1880 and 1930 . Around the end of the 19th century, when the proliferation of factories turned it into the region's main industrial pole as well as one of the most significant in the country as a whole, it was nicknamed "Manchester Mineira" (or the Manchester of Minas Gerais State), particularly due to the architectural style aspects that in common with those then current in Great Britain.

As of the 1930s, the local industry was hit by the crisis, various manufacturing establishments entering a process of decline and obsolescence, eventually shutting down. Few traditional examples have survived the neglect, demolition and reform programmes that have significantly reduced the authenticity and integrity of the original architectural characteristics. Out of this group, only eleven remain partially protected by the local authorities, and only one benefits from full protection.

Within the universe of the city's industrial heritage, Fábrica dos Ingleses [the English Factory] is outstanding, constituting a paradigmatic example of the aforementioned trajectory of peak, crisis, neglect, and the ensuing controversial protection criteria. Founded in 1883 and considered the first large scale factory in the city, this industrial complex underwent some modifications and expansions before ceasing activity in the mid-1980s. After years of abandonment, it was partially demolished in the late 1990s. 
The remnants of the original complex, a shed, a house and a chimney constructed at the beginning of the 20th century, were listed in 2003. The derelict land resulting from the demolition was allocated to the construction of a complex of commercial establishments, the occupation of which has not even been consolidated yet.

Based on analysis of this factory's controversial trajectory, this work is intended to reappraise the protection and conservation policy in Juiz de Fora, especially in relation to its set of traditional industrial establishments, whose historical, artistic and affective importance require, in the author's view, a different attitude. This reassessment is contextualized through the specialized conservation literature with emphasis on industrial heritage, above all drawing on the British experience, given the country's prominence in the international scenario regarding this theme and the cited resemblances with the circumstances of Juiz de Fora.

Key-words: Preservation of industrial architecture. Industrial heritage, Juiz de Fora, MG, Brazil. The English Factory, Juiz de Fora, MG.

\section{1 - Apogeu e declínio da Manchester Mineira}

As origens da cidade de Juiz de Fora estão ligadas à fase da exploração do ouro no interior do Brasil, do final do século 17 até o início do século 19, especialmente na região que ficou conhecida como Minas Gerais que corresponde atualmente a um dos principais estados brasileiros em termos sociais, econômicos, políticos e culturais. Nesta época, a Coroa Portuguesa construiu o Caminho Novo em opção ao Velho, bem mais extenso, que se constituiu na principal via de escoamento da produção do ouro desta região para a sede do Brasil Colonial situada na cidade do Rio de Janeiro. A Zona da Mata, local onde Juiz de Fora iria se consolidar como cidade, não era uma região produtora de ouro. Entretanto, nela, ao longo deste caminho, formaram-se diversos entrepostos de fiscalização da rota do ouro e respectivas atividades de apoio como estalagens e pousadas.

Um dos marcos da formação de Juiz de Fora foi a construção da Fazenda do Alcaide-Mor no início do século 18, atualmente conhecida como Tapera. Após duas décadas, o povoado que surgiu em torno deste local foi elevado à categoria de vila, 
a de Santo Antônio do Paraibuna, que se transformou em cidade na década de 1860. O nome atual, Juiz de Fora, foi dado em 1865.

A consolidação de Juiz de Fora como entreposto comercial foi decisiva para transformá-la na principal referência da região na fase da produção do café que vai da segunda metade do século 19 até a década de 1930. Praticamente toda a Zona da Mata seria ocupada por grandes fazendas de café que iriam impulsionar o desenvolvimento de várias cidades. Para facilitar o escoamento desta produção e de circulação de mercadorias foi construída a Estrada União Indústria, a qual foi inaugurada em 1861. Logo em seguida, este empreendimento foi superado pela implantação da Estrada de Ferro Central do Brasil, cuja estação de Juiz de Fora foi inaugurada em 1875.

Os excedentes de recursos econômicos da produção do café, a melhoria da acessibilidade à região, a presença de mão de obra relativamente qualificada dos imigrantes (principalmente de alemães e italianos), entre outros fatores, criaram as condições favoráveis para o surto de industrialização da cidade a partir da década de 1880. Estes atrativos atraíram a atenção de alguns empreendedores. Um dos mais referenciados é Bernardo Mascarenhas que construiu a Companhia Têxtil Bernardo Mascarenhas - CTBM em 1888 e no ano seguinte a primeira usina hidroelétrica da América do Sul.

No rastro deste e de outros empreendimentos de médio e de grande porte, a maioria deles ligados à tecelagem, Juiz de Fora transformou-se no principal centro industrial de Minas Gerais e um dos mais significativos do Brasil, tendo a concorrência de São Paulo e do Rio de Janeiro, os dois maiores pólos fabris do país nesta ocasião (SINGER, 1974). Cogitou-se inclusive de transformá-la na capital deste estado em substituição a Ouro Preto, sede das Minas Gerais na fase do ouro. Entretanto, pressões políticas abortaram esta pretensão em detrimento de Belo Horizonte, que posteriormente transformou-se numa das principais regiões metropolitanas do país.

O auge da industrialização de Juiz de Fora ocorreu concomitantemente com o apogeu do período cafeeiro que também vai de 1880 a 1930. Em 1907 existiam 57 estabelecimentos industriais com atividades diversificadas (PIRES, 2004, p. 43-44). 
A maioria deles possuía aspectos arquitetônicos semelhantes às fábricas inglesas, sobretudo as alvenarias de tijolos maciços aparentes das fachadas. O conjunto arquitetônico composto por estas edificações conferia uma atmosfera britânica a Juiz de Fora e serviu de inspiração para o codinome "Manchester Mineira".

A partir da década de 1930, a industrialização de Juiz de Fora entra em decadência juntamente com as atividades ligadas à produção do café. Além do declínio econômico das fazendas cafeeiras, toda a Zona da Mata perde a ascendência regional para Belo Horizonte. Em termos nacionais, a industrialização mineira sofre concorrência com o Rio de Janeiro, capital do país neste momento e São Paulo, a qual vai se transformar na maior metrópole brasileira da década de 1950 em diante. Ressalta-se também que o parque fabril da cidade não se diversificou e nem se modernizou.

Os investimentos industriais retornaram timidamente à região através do processo de descentralização da produção brasileira a partir da década de 1970 estimulado também pelo programa de melhoria de infraestrutura urbana do Banco Interamericano conhecido como "Programa Cidade de Médio Porte". Por outro lado, a cidade vai se firmar na Zona da Mata e arredores como pólo prestador de serviços, especialmente na área de ensino com a implantação da Universidade Federal de Juiz de Fora em 1960 e diversos estabelecimentos de ensino privados dos anos 1990 em diante.

2 - A destruição e os sobreviventes do parque industrial de Juiz de Fora

A desindustrialização causada pela revisão das formas de produção provocou a partir da década de 1970 efeitos devastadores em locais estruturados pela industrialização. Por conta dessas transformações, países como Estados Unidos e Grã-Bretanha, testemunharam a dispersão de empresas para países periféricos que deixou para trás um estoque de edificações vazias e subutilizadas nas zonas portuárias, distritos industriais e áreas centrais de negócios. A descentralização também ocorreu na direção da periferia das grandes cidades destes países, próximas aos grandes entroncamentos rodoviários. Algumas iniciativas se transformaram em complexos industriais fundamentados na associação de conhecimento científico e tecnológico, as quais ficaram conhecidas como 
"tecnopólos" definidos por Hermes Tavares (1994, p. 270) como "sítios de acolhimento de complexos industriais que se fundam na associação de conhecimento científico e tecnológico". O exemplo paradigmático situa-se no Vale do Silício, na Califórnia, Estados Unidos. A versão britânica localiza-se ao longo do corredor viário denominado M4, próximo a Londres.

No Brasil, a dispersão de atividades industriais ocorreu ao longo da década de 1970, das principias metrópoles (São Paulo e Rio de Janeiro) para as secundárias (Belo Horizonte e Porto Alegre), e posteriormente para cidades de médio porte. No caso brasileiro, os trechos das metrópoles mais afetados foram as áreas centrais. Quanto aos tecnopólos, segundo Tavares (1994, p. 270):

\footnotetext{
são vários os sinais deste fenômeno no contexto brasileiro. Complexos de inovação tecnológica existem há algumas décadas no eixo Rio-São Paulo e outros estão em implantação ou planejamento, em áreas mais distantes do centro dinâmico do país (por exemplo, em Campina Grande).
}

Em Juiz de Fora, a desindustrialização é anterior e ocorre pelos fatores expostos anteriormente, ou seja, em função da estagnação do parque industrial e pela concorrência apontada.

Convém destacar que a localização destes estabelecimentos industriais subutilizados e/ou vazios próximos às áreas centrais, zonas portuárias dotadas de boa infraestrutura urbanas, eixos ferroviários e viários estratégicos também colaborou para a destruição deles em função da valorização destas localidades no mercado imobiliário. Vários empreendimentos foram implantados nestes locais às custas de demolições de exemplares arquitetônicos ignorados pelas políticas de proteção do patrimônio cultural.

Esta atitude relembra a trajetória da proteção do patrimônio cultural, sobretudo de edificações e de áreas urbanas, a qual foi marcada inicialmente por momentos de valorização de bens de notáveis méritos artísticos e de caráter monumental e/ou por fatos memoráveis do passado. Os vários questionamentos observados ao longo deste contexto em relação a esta forma positivista de se proteger culturas pelo 
mundo afora provocaram a revisão dos indicadores de valores que justificavam as salvaguardas. Este fenômeno também atingiu a estruturação do Conselho Internacional de Monumentos de Sítios Históricos - ICOMOS que a partir da década de 1980 passou a conviver com outras organizações similares dedicadas exclusivamente a conservação de bens culturais marginalizados pelos instrumentos de proteção legal de nações, estados, localidades, etc. Situam-se neste contexto, por exemplo, a redefinição do papel da Arquitetura Moderna através das mobilizações do DOCOMOMO fundado em 1988 e do patrimônio industrial defendido pelo The International Committee for the Conservation of the Industrial Heritage - $\mathrm{TICCIH}$, criado em 1999, e que atualmente conta com representações em 43 países e assessora o ICOMOS nesta questão através de um comitê científico específico.

As implantações das fábricas de Juiz de Fora no período da Manchester Mineira repetem a tendência citada e concentraram-se próximas ao centro, nas cercanias da principal estação ferroviária e nas imediações da parte central, trechos que se valorizaram na expansão urbana da cidade. $O$ fechamento destes estabelecimentos determinou a venda da maioria deles para empreendedores que não levaram em consideração a importância deste patrimônio cultural para a construção da memória local, especialmente do período considerado mais próspero da cidade em termos sociais, econômicos e culturais. Esta destruição foi total em determinadas situações e parcial em outros. Os exemplares que conseguiram sobreviver encontram-se majoritariamente protegidos pela Prefeitura. Deste universo, restam apenas onze edificações que se encontram parcialmente tombadas através de critérios questionáveis que se restringem à proteção de chaminés isoladas, fachadas principais (algumas delas convertidas em pórticos para novos prédios) e parte de volumetrias de edificações. Somente um deles possui proteção integral que abrange inclusive o maquinário original, a Usina de Marmelos, a primeira usina hidrelétrica da América do Sul, conforme mencionado acima, cuja proteção também é feita pelo Governo do Estado de Minas Gerais e inexplicavelmente ainda não contemplada pela política de proteção do Governo Federal.

Convém destacar a predominância da proteção de fachadas e coberturas na política de proteção do patrimônio cultural da cidade de Juiz de Fora, sobretudo nos casos 
de edificações. O emprego deste critério equivale a cerca de setenta a oitenta por cento dos tombamentos efetuados. Muitos deles ignoraram interiores e outros aspectos arquitetônicos relevantes como nos casos de parte da antiga sede da Prefeitura, as "Repartições Municipais", a casa da Família Colluci, Castelinho da Família Bracher, Capela de Santa Terezinha, Igreja da Glória, Instituto Granbery, o Hotel São Luiz, entre vários outros. Na literatura especializada de conservação, esta atitude é rotulada como fachadismo (RICHARDS, 1994) e "coberturismo" (SAMPAIO, 2005, p. 65) e é muito criticada em função do comprometimento da autenticidade e integridade dos conjuntos arquitetônicos abrangidos. Entretanto, este fenômeno é mundial e se aplica também em larga escala na categoria de "bens preservados" das Áreas de Proteção do Ambiente Cultural - APACs criadas pela Prefeitura do Rio de Janeiro. David Highfield (1991), da mesma forma, indica inúmeros casos de fachadismos e "coberturismos" executados em edificações protegidas no Reino Unido.

O saldo das ações da desindustrialização e da política de proteção de Juiz de Fora gerou um grupo de edificações parcialmente caracterizado. Dentre o universo do patrimônio cultural industrial da cidade, os casos mais representativos desta situação são os fachadismos e os "coberturismos" do Curtume Krambeck (Figura 1), da Companhia Fiação e Tecelagem Santa Cruz (Figura 2), dos Galpões da antiga Garagem da Companhia Energética de Minas Gerais/CEMIG (Figura 3) e da Companhia Têxtil Ferreira Guimarães, antiga Fábrica dos Ingleses, que será discutida a seguir. As exceções ficam por conta das conversões da antiga fábrica Bernardo Mascarenhas num centro cultural mantido pela prefeitura e na transformação da Usina de Marmelos em um museu temático da história da energia elétrica, a qual encontra-se sob responsabilidade da Universidade Federal de Juiz de Fora através de um convênio firmado com a CEMIG.

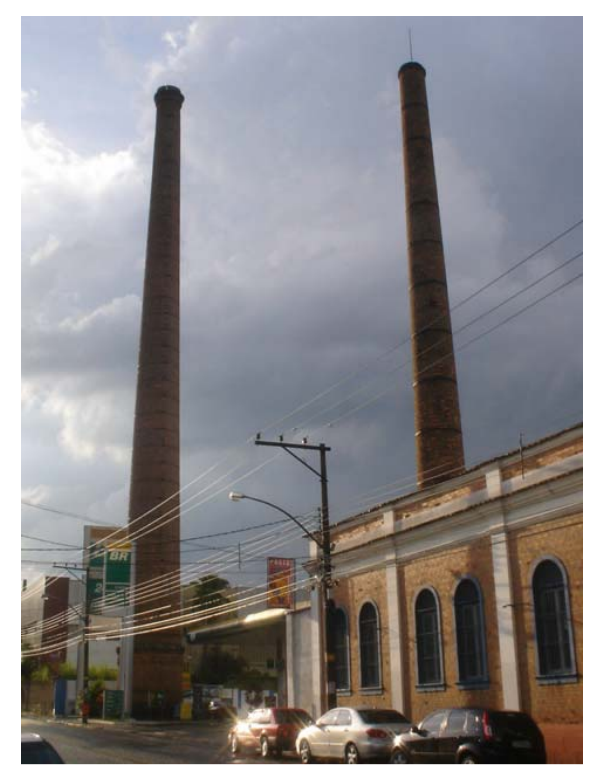

Figura 01 - Curtume Krambeck. Fotografia: Julio Cesar Ribeiro Sampaio, 2010. 


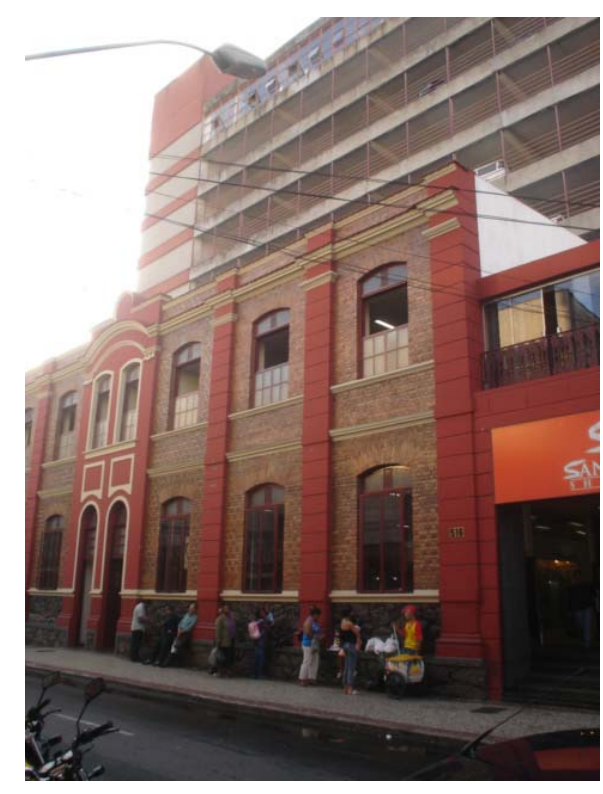

Figura 02 - Companhia Fiação e Tecelagem Santa Cruz.

Fotografia: Julio Cesar Ribeiro

Samnaio. 2010.

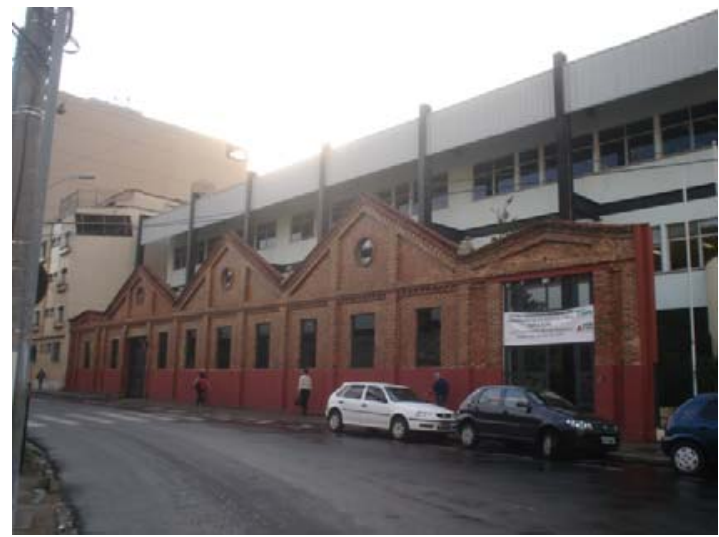

Figura 03 - Garagem da Companhia Energética de Minas Gerais/CEMIG. Fotografia: Julio Cesar Ribeiro Samnaio. 2010.

\section{3 - A Fábrica dos Ingleses}

A Fábrica dos Ingleses era assim conhecida por se tratar de um empreendimento de responsabilidade de um consórcio das firmas Morrit, Stiele \& Withaker que adquiriu um terreno da Cia União Indústria em 1853 para a construção da primeira fábrica de tecidos de Juiz de Fora (JUIZ de Fora..., [s.d.], p. 88). Esta fábrica, entretanto, iniciaria suas atividades pioneiras somente em 1883 com um staff de 210 operários, alguns deles membros da Cia União Indústria que construiu a estrada que ligou Juiz de Fora a Petrópolis a partir de 1861.

A tecnologia empregada era de ponta. A fábrica utilizava uma turbina hidráulica inédita no Brasil que aproveitava a força motriz gerada pelas águas da cachoeira do Ribeiro da Cascata para gerar energia elétrica antes da existência da usina hidrelétrica de Bernardo Mascarenhas (PREFEITURA MUNICIPAL DE JUIZ DE FORA, Processo 4486, 1997). A tecelagem ficou conhecida como "Fábrica dos Ingleses", um ano antes do empreendimento paradigmático de Mascarenhas. 
Entretanto, a denominação oficial era "Fábrica de Tecidos Industrial Mineira." As inovações tecnológicas da Fábrica dos Ingleses incluíram também a utilização de energia elétrica para a iluminação, a qual foi inaugurada em 1887.

De março de 1889 em diante, este conjunto fabril passou a se denominar Companhia de Fiação e Tecelagem Industrial Mineira, a qual foi incorporada por outra empresa do mesmo ramo, a Ferreira Guimarães, em 1942, nome pela qual as edificações remanescentes do complexo industrial são conhecidas atualmente. A produção de tecidos encerrou-se na década de 1980 e foi deslocada para outra unidade da empresa (PREFEITURA MUNICIPAL DE JUIZ DE FORA, Processo 4486, 1997).

Após anos de subutilização, a Prefeitura iniciou em 1997 o processo de tombamento da Ferreira Guimarães. Os proprietários questionaram a iniciativa alegando equivocadamente que o complexo industrial estava descaracterizado, mal conservado e não representava a arquitetura industrial típica da cidade, da Manchester Mineira em especial (PREFEITURA MUNICIPAL DE JUIZ DE FORA, Processo 4486, 1997). O tombamento foi concluído em 2003 e se restringiu ao trecho da fábrica construído no início do século 20 pela Cia Pantaleone Arcuri, uma das principais referências da história da arquitetura da cidade. Neste galpão funcionavam o escritório e a expedição comercial da fábrica, o qual, neste momento, abriga as instalações de uma cozinha industrial. O acabamento das fachadas, composto por alvenarias de tijolos aparentes, se enquadra no padrão estilístico da Manchester Mineira. As duas chaminés contíguas ao prédio também foram incluídas nesta proteção. Os demais trechos incorporados ao volume original durante o século 20, o qual representava cerca de oitenta e cinco por cento de todo o conjunto, foram desprezados e demolidos em 2003 gerando protestos isolados numa matéria publicada pelo jornal Tribuna de Minas em 15 de junho deste ano (JUIZ de Fora, 2003) (Figuras 4 e 5). No ano seguinte, a Prefeitura tombou uma edificação inserida no contexto do antigo complexo fabril da Ferreira Guimarães, a qual servia de hospedaria e era denomina "Casa dos Hóspedes".

Os Decretos Municipais que tombaram o escritório (Figura 6), as chaminés (Figura 7) e a hospedaria ("Casa de Hóspedes") da antiga Fábrica dos Ingleses (Figura 8) 


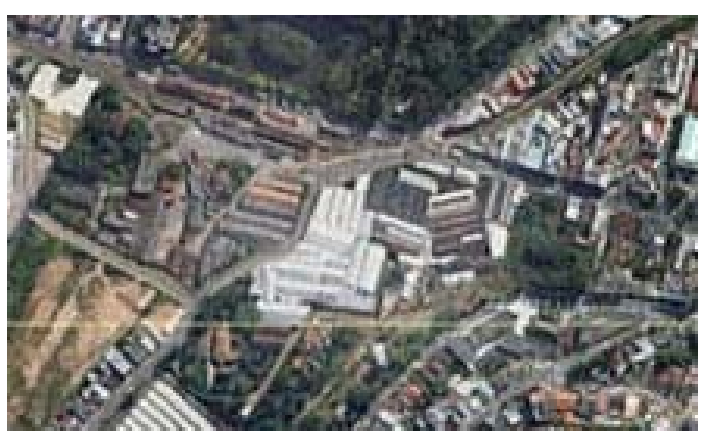

Figura 04 - Fábrica dos Ingleses antes da demolição. Fonte: Prefeitura Municipal de Juiz de Fora, c. 1986.

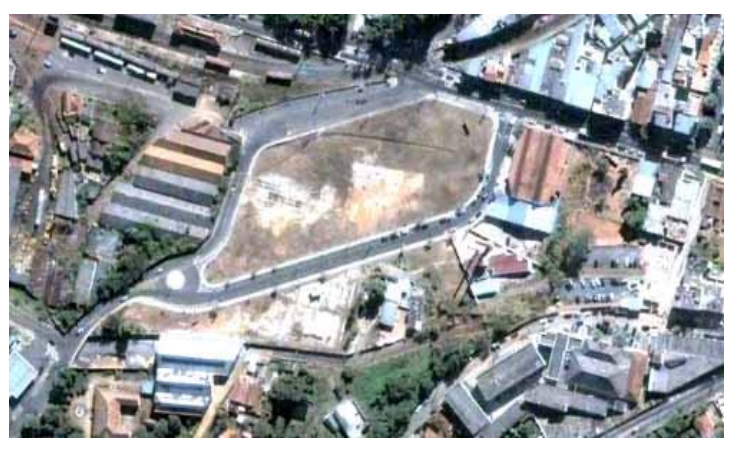

Figura 05 - Fábrica dos Ingleses depois da demolição. Fonte: Prefeitura Municipal de Juiz de Fora, c. 2006.

reconhecem que estes elementos arquitetônicos remanescentes do complexo industrial original eram partes integrantes da "primeira unidade fabril de Juiz de Fora" e da "da primeira fábrica têxtil da cidade" (PREFEITURA MUNICIPAL DE JUIZ DE FORA, Decretos 7913/2003 e 8380/2004).

Pode-se afirmar que faltou engajamento da política de conservação da cidade na preservação de um dos principias bens culturais representante do período histórico mais festejado em toda a esfera intelectual de Juiz de Fora. Esta lacuna na memória da cidade pode ser descrita como uma das maiores perdas ou talvez a

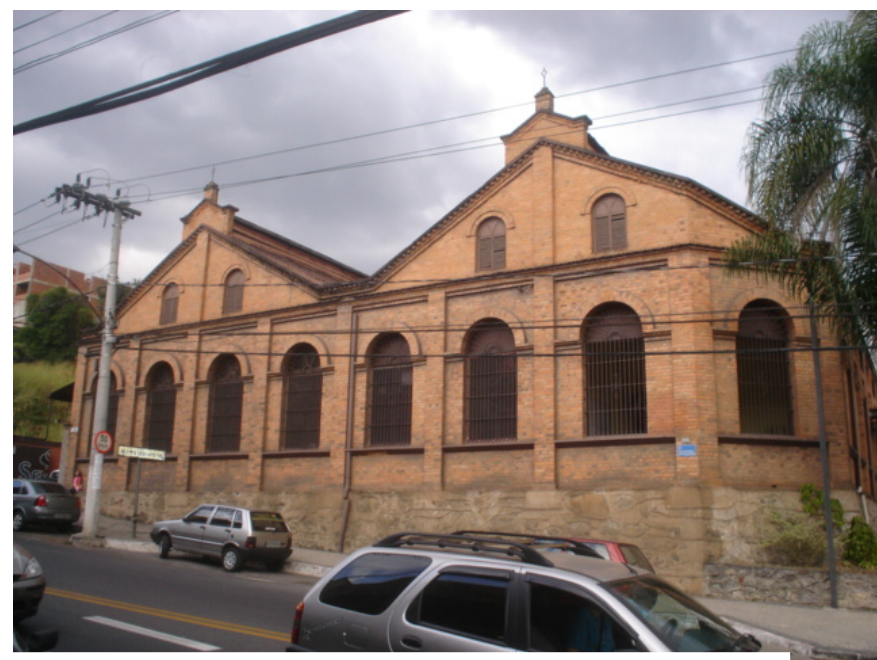

Figura 06 - Escritório da Fábrica dos Ingleses construído no início do século XX pela Pantaleone Arcuri.

maior delas do patrimônio cultural local com repercussões regionais e até nacionais em função da primazia da empreitada e das respectivas inovações tecnológicas apontadas. A falta de visão dos proprietários compactuada pelo poder público local se sobressai, mais ainda, em função do que está sendo proposto como empreendimento imobiliário para o lote resultante da demolição da parte majoritária da Fábrica dos Ingleses (Figura 9). Nele se propôs um complexo de uso misto com lojas, escritórios, estabelecimentos comerciais e unidades 
residenciais, o qual poderia ser implantado na estrutura física da fábrica nos moldes das experiências britânicas e americanas de regeneração urbana de antigos complexos industriais e portuários, das Docklands Londrinas (Figura 10), dos portos de Boston, Nova lorque e de outros casos vastamente citados na literatura especializada de conservação de edificações de áreas urbanas (COLQUHOUN, 1995; COUPLAND, 1997). O que foi comercializado e construído até o momento é fruto de um padrão construtivo indefinido que não reflete o que se tem de melhor na produção arquitetônica atual da cidade.

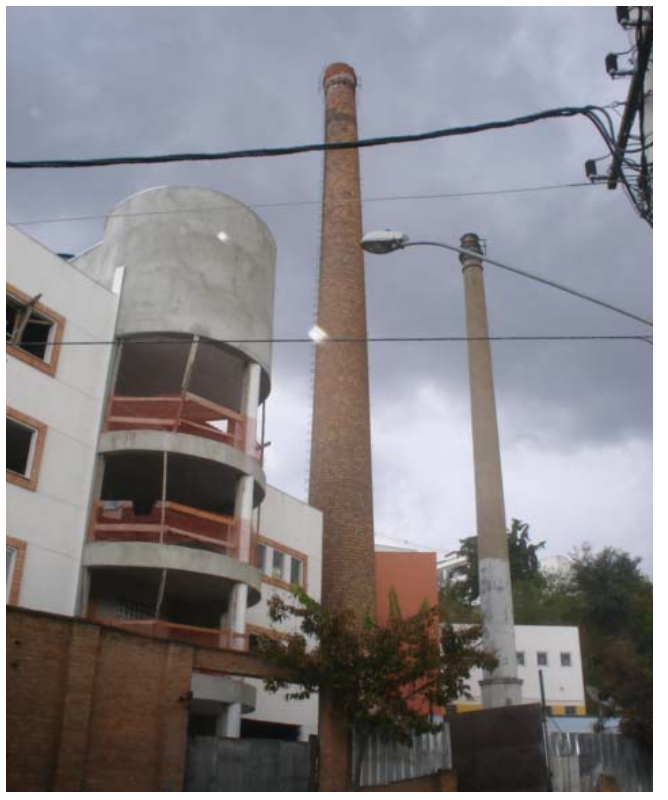

Figura 07 - Chaminé tombada. Fotografia: Julio Cesar Ribeiro Sampaio, 2010.
A regeneração urbana britânica merece uma evidência especial, sobretudo em função da analogia de Juiz de Fora com a cidade de

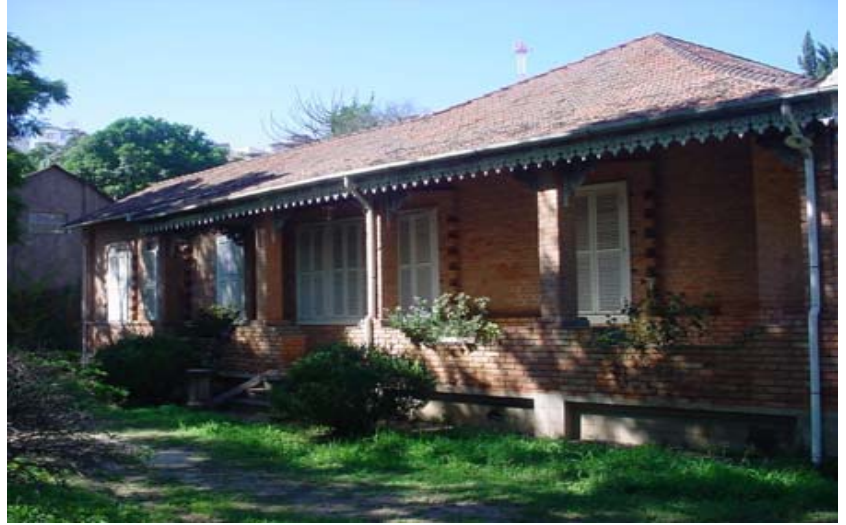

Figura 08 - Casa de Hóspedes. Fotografia: Julio Cesar Ribeiro Sampaio, 2010.

Manchester. Na Inglaterra, as medidas concretas para se reverter o quadro de abandono dos locais afetados pela desindustrialização tiveram início em 1978 com a criação do Urban Regeneration Act, por parte do governo britânico, que previa um conjunto de estratégias voltadas para a recuperação física, econômica e social das áreas degradadas, a maioria delas de relevância histórica. Somente na década seguinte estas diretrizes foram colocadas em prática. Porém, sob nova ótica com ênfase nos aspectos físicos e econômicos, em detrimento do enfoque social adotado nas intervenções do Estado de Bem Estar Social do pós-guerra.

A principal estratégia de regeneração urbana foram os flagships projects, projetos âncoras, que tinham por objetivo servir de catalisadores da reestruturação física e 
econômica dos locais onde eram implantados. Através destes empreendimentos várias zonas portuárias e antigos complexos industriais foram regenerados e transformados em complexos residenciais, de escritórios e de estabelecimentos comerciais luxuosos. Alguns deles como a London Dockland, zona portuária Londrina, na parte leste da cidade, ao longo do Rio Tâmisa, executada no decorrer da década de 1980, tornaram-se paradigmas contestados por uns (BIANCHINI et al, 1992) e defendidos por outros (SMYTH, 1994).

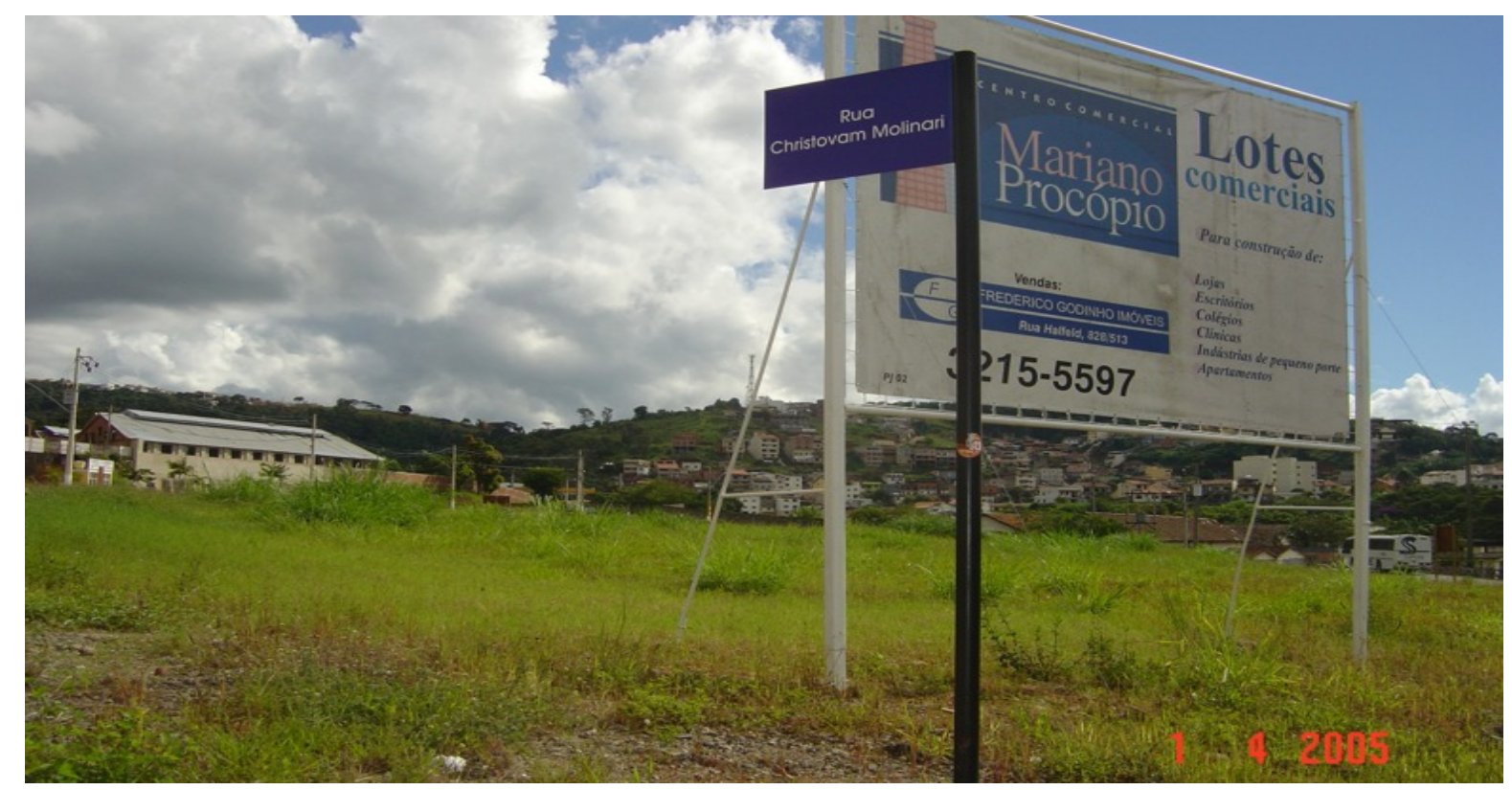

Figura 09 - Lote resultante da demolição da Fábrica dos Ingleses. Fotografia: Julio Cesar Ribeiro Sampaio, 2010.

Em 1990, a União Europeia publicou um Green Paper, documento contendo propostas de políticas urbanas na área de meio ambiente construído, propondo aos países membros especial atenção em relação ao uso indiscriminado do automóvel. Uma das principais recomendações foi a utilização efetiva dos centros das cidades como local de moradia para se tentar restabelecer o percurso casa-trabalho sem depender de transportes coletivos e individuais (com exceção da bicicleta). Esta proposta foi absorvida na política urbana britânica através do Planning Policy Guide 6-PPG 6, Diretrizes de Política de Planejamento Número Seis, publicada pelo DoE, Departamento de Meio Ambiente, em 1993.

O PPG 6 tinha como uma das principias diretrizes a recomendação do uso misto nos 
planos diretores das cidades. Esta proposta não se limitou às cidades já existentes. Alguns projetos de novos assentamentos urbanos também incorporaram o uso misto na tentativa de se recriar a polifuncionalidade das cidades tradicionais. Duas das principais referências sobre o tema são "Urban Villages: a concept for creating mixed-use urban development on a sustainable scale" (URBAN VILLAGE GROUP, 1992) e "The Essex Design Guide for Residential and Mixed Use Areas (ESSEX PLANNING OFFICERS ASSOCIATION, 1997). Entretanto, de acordo com Shankland Cox (1993, p. 25), a população e o mercado imobiliário em países como a Grã-Bretanha ainda possuem grande resistência ao uso misto. Petherick e Barnett (1998, p. 11), anotam que as principais razões para este ceticismo baseiam-se no aumento considerável de ruídos produzidos por estabelecimentos comerciais e pelo aumento do fluxo de veículos. Outro importante aspecto destacado por estas autoras é a necessidade de grandes investimentos na melhoria de transportes públicos, estacionamentos, segurança e equipamentos sociais coletivos para atrair a atenção de potenciais moradores para as áreas centrais.

O que aconteceu na Fábrica dos Ingleses demanda uma reflexão do modelo de desenvolvimento da cidade

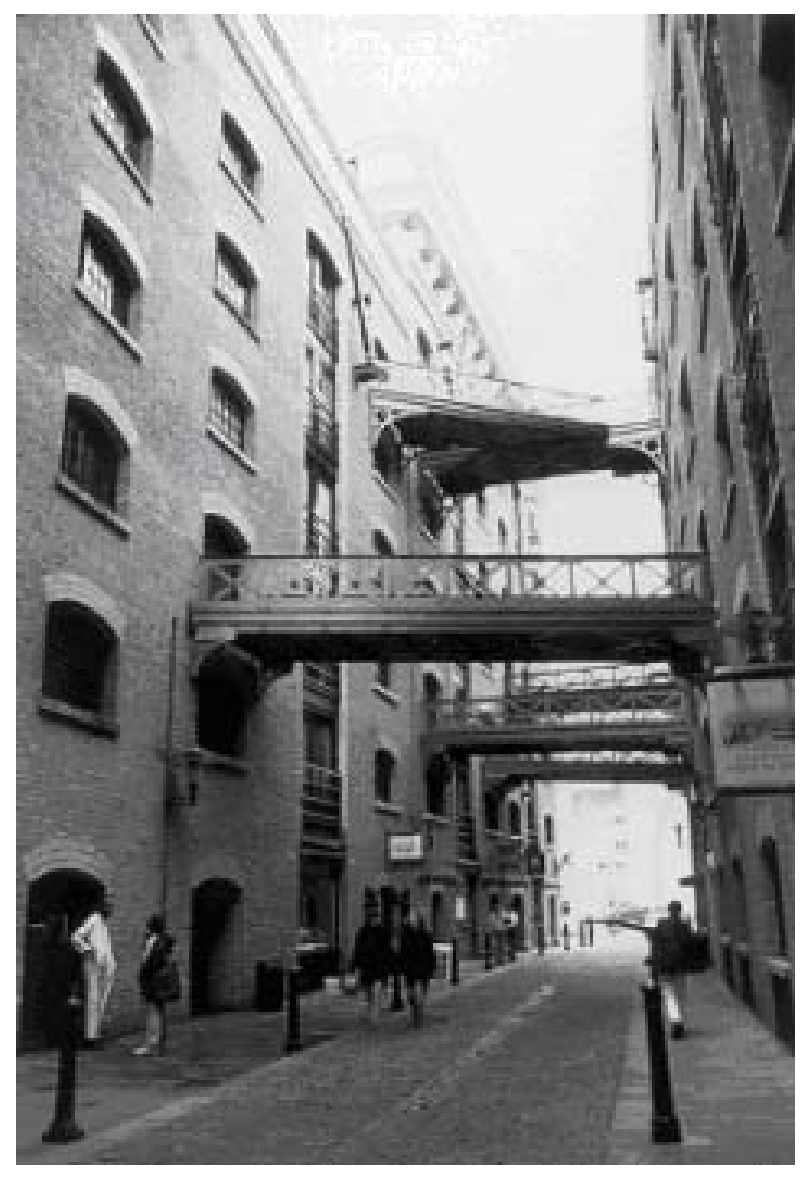
e das respectivas políticas urbanas onde a questão da conservação, conforme observado no caso britânico, poderia desempenhar um importante papel. É relevante destacar que a apropriação do patrimônio cultural por tipos

Figura 10 - Shad Thames, Londres. Armazéns convertidos num complexo de uso misto (unidades residenciais, escritórios e lojas). Fotografia: J ulio Cesar Ribeiro Sampaio, 1996. diferenciados de usuários e suas 
atividades econômicas agregam valores sociais e econômicos às edificações e áreas urbanas protegidas e sustentam as estratégias de conservação. Esta atitude permite também a incorporação da memória da cidade na vida cotidiana atual.

Quanto ao fachadismo e o "coberturismo" dos tombamentos de Juiz de Fora e também de várias outras cidades, que atualmente são rotulados como retrofit, existe um consenso entre os estudiosos da conservação de que o emprego destes critérios desmedidos na revitalização representa "a mais drástica intervenção de conservação em edificações históricas" (TIESDELL; OC; HEATH, 1996, p. 175). Entretanto, Peter Larkham (1996, p. 243) minimiza estes comentários relatando que fachadismo representa na realidade uma conciliação entre políticas de conservação das autoridades locais, pressões econômicas e a vontade da população de preservar edificações. A tomada de decisões contra ou a favor do fachadismo é apontada por Richards (1994) como um processo complexo que envolve negociações entre um leque de atores incluindo os responsáveis pela elaboração de políticas urbanas. Estes últimos são rotulados por este autor como aqueles que passivamente ou ativamente promovem o fachadismo como parte das estratégias de conservação urbana.

Portanto, cabe discutir se a experiência da política de proteção de Juiz de Fora pode servir de subsídios na reavaliação de fachadas principais, coberturas, partes de volumetrias e chaminés como os únicos elementos realmente representantes de um todo arquitetônico singular, no caso deste trabalho, de um dos conjuntos fabris históricos mais relevantes do Brasil que insiste em sobreviver e que representa, segundo a literatura especializada da história local, um dos principais legados da fase áurea da cidade, da Manchester Mineira. A industrialização particulariza Juiz de Fora da mesma forma que a fase do ouro personaliza Ouro Preto, São João del Rei e as demais localidades mineiras denominadas "Cidades Históricas".

\section{Referências bibliográficas}

BIANCHINI et al. Flagship projects in urban regeneration. In: HEALEY, P. et al (Ed.). Rebuilding the city: property-led regeneration. London: E. \& FN. Spon, 1992. p. 245-255. 
COLQUHOUN, Ian. Urban regeneration: an integral perspective. London: Batsford, 1995.

COUPLAND, Andy (Ed.). Reclaiming the city. London: E. \& FN, 1997.

COX, Shankland. Mixed uses in buildings, blocks and quarters. Brussels: European Commission, 1993.

ESSEX PLANNING OFFICERS ASSOCIATION. The Essex Design Guide for Residential and Mixed Use Areas. Essex: Essex Planning Officers Association, 1997.

EUROPEAN COMMISSION. Green Paper on the Urban Environment. Brussels: Commission to the Council and Parliament, 1990.

HIGHFIELD, D. The construction of new buildings behind historic facades. London: E. \& FN. Spon, 1991.

JUIZ de Fora em 2 tempos. Tribuna de Minas, Juiz de Fora: Esdeva, [s.d.]. p. 88.

JUIZ de Fora - o Processo de Tombamento. Tribuna de Minas, Juiz de Fora, 15 jun. 2003.

LARKHAM, Peter J. Conservation and the city. London: Routledge, 1996.

PETHERICK, Ann; BARNETT, Ruth. Living over the shop: an assessment of the potential in Stockton-on-Tees. Stockton: Stockton City Challenge, 1998.

PIRES, Anderson. Café e indústria em Juiz de Fora: uma nota introdutória. In: NEVES, José Alberto Pinho et al. Juiz de Fora: história, texto e Imagem. Juiz de Fora: FUNALFA, 2004. p. 27-49.

PREFEITURA MUNICIPAL DE JUIZ DE FORA. Processo Municipal Número 4486/97.

PREFEITURA MUNICIPAL DE JUIZ DE FORA. Decreto Municipal Número 7913 de 15/07/2003.

PREFEITURA MUNICIPAL DE JUIZ DE FORA. Decreto Municipal Número 8380 de 04/11/2004.

RICHARDS, Jonathan. Facadism. London: Routledge, 1994.

SAMPAIO, Julio Cesar Ribeiro. Corredor cultural: fachadas preservadas, espaços subutilizados, Revista Topos, v. 4 , p. $61-68,2005$.

SINGER, Paul. Desenvolvimento econômico e evolução urbana. São Paulo: Companhia Editora Nacional, 1974.

SMYTH, Hedley. Marketing the city: the role of flagship development in urban regeneration. London: E. \& FN. SPON, 1994.

TAVARES, Hermes Magalhães. Complexos de alta tecnologia e reestruturação do espaço. In: SANTOS, Milton et al (Org.). Fim de século e globalização. São Paulo: HUCITEC, 1994. p. 270-284. 
TIESDELL, Steven; OC, Turner; HEATH, Tim. Revitalizing historic urban quarters. Oxford: Architectural Press, 1996.

URBAN VILLAGE GROUP. Urban villages: a concept for creating mixed-use urban development on a sustainable scale. S.I.: BAS Printers, 1992.

\section{Créditos}

* Arquiteto e Urbanista, Mestre e Doutor em Conservação e Arquitetura, Professor Adjunto IV do Curso de Arquitetura e Urbanismo do Departamento de Arquitetura e Urbanismo do Instituto de Tecnologia da Universidade Federal Rural do Rio de Janeiro.

E-mail: julio.sampaio.ufrrj@gmail.com 